\title{
Prevalência de lesões podais e graus de claudicação em vacas da raça Jersey, em lactação, mantidas em sistema free-stall e semiconfinamento
}

Juliana das Chagas Goulart ${ }^{[a]}$, Francisco Armando de Azevedo Souza ${ }^{[b]}$, Rodolfo Rando[a], Thais Helena Constantino Patelli[b], Emília de Paiva Porto ${ }^{[b]}$, Vitor Bruno Bianconi Rosa ${ }^{[b]}$

\footnotetext{
[a] Medicina Veterinária, Universidade Estadual do Norte do Paraná (UENP), Bandeirantes, PR, Brasil

[b] Setor de Veterinária e Produção Animal, Universidade Estadual do Norte do Paraná (UENP), Bandeirantes, PR, Brasil
}

*Autor correspondente

e-mail: jugoulart8@hotmail.com

\section{Resumo}

As lesões podais em bovinos leiteiros são um problema crescente, devido à intensificação dos sistemas de exploração. Os prejuízos devido às lesões são referentes à queda na produção leiteira, redução da fertilidade, descarte precoce dos animais e custos com tratamentos. Isto posto, este trabalho teve como objetivo apresentar dados sobre a prevalência de afecções podais e graus de claudicação de vacas em lactação da raça Jersey, mantidas em sistemas de confinamento free-stall e de semiconfinamento, em propriedades do Paraná. Avaliou-se 68 animais, dos quais 22 mantidos em sistema free-stall (11 primíparas com idade média de 31 meses, e 11 multíparas com idade entre 4 e 10 anos) e 46 mantidos em semiconfinamento (23 primíparas com idade média de 30 meses e 23 multíparas com idade entre 4 e 10 anos). Após a seleção, atribuiu-se aos indivíduos o escore de claudicação e a classificação das lesões podais quando presentes. As variáveis estudadas foram os tipos de lesões encontradas, escore de claudicação dos animais examinados nos diferentes sistemas de produção e a diferença das lesões entre vacas primíparas e multíparas. A ocorrência de lesões foi comparada entre os dois sistemas, utilizando-se o teste não paramétrico de KruskalWallis. Dos 22 animais mantidos em free-stall, uma vaca (4,54\%) apresentou claudicação de grau 2 e duas $(9,09 \%)$ apresentaram claudicação de grau 3. De um total de 46 vacas mantidas em semiconfinamento, quatro $(8,69 \%)$ apresentaram claudicação de grau 2 e três vacas $(6,52 \%)$ apresentaram grau 3. Quanto às lesões podais, as vacas mantidas em free-stall apresentaram um total de 436 lesões com uma média de 19,8 lesões por vaca, sendo que 58,9\% das lesões estavam em membros pélvicos, com os dígitos laterais $(55,25 \%)$ mais acometidos. Os indivíduos mantidos em semiconfinamento apresentaram 721 lesões, com uma média de 15,67 lesões por vaca, sendo que 52,57\% estavam nos membros pélvicos, com 50,66\% dos dígitos laterais acometidos. As vacas primíparas em free-stall apresentaram maior prevalência $(\mathrm{P}<0,05)$ quanto às lesões doença da linha branca e sola dupla, enquanto que as multíparas apresentaram maior 
prevalência $(\mathrm{P}<0,05)$ de sola dupla, dermatite interdigital e sola plana. Os resultados quanto às lesões se devem ao manejo realizado na propriedade. Alterações bruscas na dieta, alta taxa de concentração de animais, utilização incorreta ou ausência de pedilúvio, e falta de casqueamento periódico foram os principais fatores encontrados para justificar as lesões encontradas em ambas os sistemas. Concluiu-se que no sistema free-stall houve maior prevalência das lesões doença da linha branca e sola dupla em vacas primíparas, e sola dupla, dermatite interdigital e sola plana em vacas multíparas. No sistema de semiconfinamento, as lesões com maior prevalência para as vacas multíparas foram erosão do talão e erosão axial. 